\title{
Motivations for Becoming a Police Officer: a Global Snapshot
}

\author{
Stamatis Elntib ${ }^{1,2} \cdot$ Daliborka Milincic $^{1,2}$ \\ Published online: 9 July 2020 \\ (C) The Author(s) 2020
}

\begin{abstract}
This study investigated the motives to work for the Police focusing on the differences between recruits from developing and developed countries. Age and year recruited were also accessed to ascertain whether they can account for variance in motives. A total of 233 participants from 28 countries, of which 70 were female, were recruited from active $(N=82)$ or former $(N=151)$ Police officers (mean age $=37.65, \mathrm{SD}=8.76$, range $=20-62$ ). Of the 28 countries, 16 were classified as developing and 12 as developed by the United Nations classification guide. An adapted 14-item survey was used based on the original scale developed by Lester (1983) listing respectively different reasons for joining the police. Participants from developing countries scored higher motives related to job availability and benefits, helping family and friends, and family influence than those from developed countries. The age recruited was negatively associated with social-capital and family influence motives and positively associated with job availability and benefits-driven motives. Those recruited more recently were more likely to score highly motives related to job availability and benefits motives. The study extended the scope of past research by recruiting a diverse sample of (former) policemen from several countries to offer a more comprehensive snapshot of the factors affecting motives.
\end{abstract}

Keywords Job availability $\cdot$ Motives $\cdot$ Police recruitment

\section{Introduction}

Policing is dangerous, exhausting, and unpredictable; still there must be a certain appeal to the profession considering that millions of people gravitate toward a career path within the Police services. Being killed in the line of duty is listed as an occupational hazard (Brandl and Stroshine 2003), yet a global average of about 300 per 100.000 inhabitants choose to and are ultimately recruited as Police officers. Police density between regions varies between very low (e.g., 241.5 per 100.000 inhabitants in Africa) and high (e.g., 435.5 per 100.0000 inhabitants in the Middle East) density areas (Harrendorf and Heiskanen 2010) as is the diversity in the crime rates across regions (United Nations 2014). Yet, the motives involved in deciding to become a Police officer are broadly predictable, ranging from altruistic ones (e.g., helping others) to purely personal such as prestige (Chu 2018; Gau et al. 2013; Lester 1983; White et al. 2010).

Stamatis Elntib

s.elntib@open.ac.uk

1 Department of Psychological Sciences, Institute of Psychology, Health and Society, University of Liverpool, Liverpool, UK

2 School of Psychology, University of Liverpool, Eleanor Rathbone Building, Bedford Street South, Liverpool L69 7ZA, UK
Those who work as Police officers are highly likely to routinely get exposed to violent incidents (Collins and Gibbs 2003) and encounter personal threats (Anshel 2000) that can ultimately affect their ability to perform their duties and negatively impact their private lives (Elntib and Armstrong 2014; Elntib et al. 2018). For example, by choosing this profession, individuals accept that they will never enjoy complete privacy and that their actions and behavior will be scrutinized even when they are off-duty. This often leads to conflicts of interest manifested in a discrepancy between officers' duties and their private involvements and relationships with neighbors and friends (Boyce and Davids 2009; Elntib et al. 2018). As communicated in the UK Police Regulations "even when off duty, Police officers do not behave in a manner that discredits the Police service or undermines public confidence" and "in determining whether a Police officer's off-duty conduct discredits the Police service, the test is not whether the Police officer discredits herself or himself but the Police service as a whole" (Home Office Guidance, 2012, p.16.).

Although such an adventurous role brings excitement that may motivate young recruits (Raganella and White 2004; Tarng et al. 2001; Wu et al. 2009), it is highly unlikely that such circumstances alone lure young men and women to become Police officers. Indeed, working in the Police offers benefits and opportunities that are rarely found in other fields of work such as early retirement (Violanti 1990), valuable 
expertise, and experience that boost their subsequent employability (Raganella and White 2004), well-paid overtime (Gershon et al. 2009; Vila 2006; Vila et al. 2002), and promotion opportunities (Cooper and Ingram 2004; Gau et al. 2013; Scarborough et al. 1999).

\section{Why Do They Want to Join the Police: In Their Own Words}

Empirical research has revealed the factors that might influence one's decision to work for the Police. Lester (1983) proposed three clusters to encompass the full list of motivations, namely, pay and security, service, and power and status. Subsequent studies used or adapted his items to come with slightly similar taxonomies or used independently, as single factors, the different motivations in subsequent analysis. For example, Wu et al. (2009) proposed five clusters of motives, namely, job security and steady salary, job qualities and functions, autonomy-power-prestige, influence from significant others, and drifting into the job- all were aligned to the three-layer structure proposed by Lester. Moon and Hwang (2004) have similarly clustered the different motives into four clusters, namely, influence from others, job security and steady salary, authority and law enforcement, and intrinsic qualities of the job. More commonly though, motivations have been treated independently by research teams, rather than processed in clusters leading to plethora of factors that may influence the original decision to work for the Police (Chu 2018; Raganella and White 2004; Tarng et al. 2001; White et al. 2010).

When the different motives are ranked in order of preference to create a hierarchy of the most influential factors, two motives prevail: job security and benefits have been ranked highly in series of studies involving officers in New York City (White et al. 2010; Raganella and White 2004), Police cadets in China (Wu et al. 2009) and South Korea (Moon and Hwang 2004), US trainees (Lester 1983), freshmen from the Central Police University in Taiwan (Tarng et al. 2001), and Taipei female officers, also in Taiwan (Chu 2018). There are cohorts within which more altruistic motives were highlighted or ranked high enough such as making a difference (Gibbs 2019) or helping others (Chu 2018); still, job security and benefits are overall the most popular reasons for joining the Police. Critically, while job benefits keep motivating recruited officers to continue working for the Police, the ranking of other motives such as keeping order and protecting others drop overtime (Oberfield 2014).

\section{Moderators of Motives and Summary of Relevant Findings}

Perhaps more complex than ascertaining the motives leading people to work for the Police is to specifically identify what drives those motives. All of the studies outlined above were conducted within a single or two Police Forces; hence, it is very hard to generalize unless the moderators are assessed on a study-to-study basis. Moreover, as noted above, most studies have scored and ranked the importance of different motives without clustering them further into broader factors. This complicates the extraction of meaningful conclusions regarding what really affects those motives as it is virtually impossible to compare study findings. Critically, research is yet to gather international samples representing more than two countries; hence, core sociodemographic influences such as economic status and age or year of recruitment remain understudied.

For example, while socioeconomic status seems to overall affect the motives, relevant research findings are rather mixed. Tarng et al. (2001) have shown that participants from low socioeconomic backgrounds were more likely to prioritize salary and benefits as motives for joining the Police than those from middle socioeconomic backgrounds. Those in the latter group were more likely to select influence of parents as top motivator. Considering that Tarng and colleagues' research was based in Taiwan where parents' concerns - centered around financial issues, job security, and social reputationare traditionally listened to, the country base of the study might be equally, if not, more influential than socioeconomic background per se. South Korea-based research has reinforced further that those from low socioeconomic backgrounds were more likely to join the Police due to job security and benefits (Moon and Hwang 2004). On the other hand, findings extracted through a sample of Chinese cadets (Wu et al. 2009) found no effects of socioeconomic status on motives. It is proposed that the mixed findings are perhaps due to the relatively small variation within studies consisting of rather uniform samples taken from a single region or country or strikingly often from a single force. On the very rare occasion where samples from two countries were used in a study (i.e., Dubai \& Taiwan), it was proposed that the respective availability of jobs within the respondents' countries may have shaped the motives (Chu 2018). Indeed, Chu (2018) has shown that while respondents from Dubai prioritized mainly altruistic reasons, respondents from Taiwan selected the role due to the financial security it offered within a context of limited job availability. Although the sample used by Chu (2018) exclusively consisted of female participants, the findings seem to mirror those from Tarng et al. (2001), also based in Taiwan, highlighting the influence of job security and benefits in deciding to become a Police officer, particularly among those from a low socioeconomic background. The current study expands on previous research by using a rather diverse sample involving (ex)officers from several countries that ultimately allow a more diverse snapshot of the motives. Critically, instead of splitting the sample into clusters of different socioeconomic statuses, this study clusters respondents' countries into developed and developing using World Bank (2014) and 
United Nations (2014) taxonomies, partially driven by the overall income grouping of its citizens.

\section{Age Matters}

There has been limited research on the age during recruitment and the year of recruitment. Since most studies have recruited compact units of Police officers or trainees, it is common that all participants have been recruited in approximately similar time periods so that the age and year of recruitment are almost identical among participants. For example, $\mathrm{Wu}$ et al. (2009) recruited cadets enrolled in four courses lasting about 4 years, hence including similarly aged (18-23 years old) recruits who happen to be enrolled during data collection (i.e., end of 2007 to early 2008). Critically, the exact age recruited in the academy, ultimately the crucial time-point upon which recruitment has started, was not reported. Similarly, Tarng et al. (2001) used a rather uniform sample consisting of freshmen in a Police course, most of whom (i.e., 94\%) aged between 18 and 20. Gibbs (2019) recruited a less uniform sample of female and minority Police applicants within a large Policing agency, hence adding some diversity in their sample but excluded white males. The job applications to work for the Police were submitted between 2009 and 2015, covering a slightly wider period of time than the abovementioned studies. Still, Gibbs (2019) did not only exclude the age (of recruitment) from the analysis but also did not report participants' age at all. Interestingly, it is not so uncommon to omit age-related information within similar research (Raganella and White 2004; White et al. 2010). Research in motivations to join the Police focusses more on gender- and race-related characteristics (Gibbs 2019; Raganella and White 2004; White et al. 2010) and less so on age of recruitment, perhaps due to the broadly similar age ranges within which most individuals are recruited (i.e., 18-21). Importantly, since most samples come from single units, there is no opportunity to explore whether the motives leading individuals to join the Police have changed overtime. In two notable attempts to investigate whether motives change overtime, Oberfield (2014) and White et al. (2010) suggested that motives among those who work for the Police are relatively stable. Still, what is unknown is whether the armies of individuals deciding to join the Police have changed their motives overtime considering that job opportunities and availability in their respective countries have also changed. To tackle the issues above, this study recruited a diverse sample ranging from those who have been recruited very young in cadet schools and Police academies (and continued to work for the Police for several years) to those recruited at a later age. Similarly, to also capture whether the motives are somewhat affected by the year of recruitment, the sample consisted of individuals recruited between 1972 and 2013.

As already mentioned, there have been several studies conducted on motivations for working for the Police. However, deeper research is warranted as the samples of participants used have been rather from one or two countries or forces and similar age sets. Inevitably, most samples included participants recruited about the same year; hence, changes in motives, overtime, were hardly assessed. This study addressed these gaps by investigating whether motives differ between Police officers who were recruited in a developing or a developed country, also assessing whether the age and year of recruitment influence the motives reported.

\section{Methods}

\section{Recruitment and Participants}

A total of 233 participants from 28 countries, of which 70 were female, were recruited from active $(N=82)$ or former $(N=151)$ Police officers (mean age $=37.65, \mathrm{SD}=8.76$, range $=20-62$ ). Of the 28 countries, 16 were classified as developing and 12 as developed (United Nations 2014; World Bank 2014) during data collection. Participants were first recruited as Police officers around the age of $20(\mathrm{M}=$ 20.23, $\mathrm{SD}=2.24$, range $=14-28$ ), between 1973 and 2013.

A cross-sectional design was used to approach a large number of potential participants. An initial sample of 422 participants, of those contacted, had agreed to voluntarily take part in the study of which 233 fully completed and returned the questionnaires. All questionnaires were electronically distributed via email. Of those, 155 were filled and returned electronically, while the remaining were returned as hard copies, filled and posted directly to the second author. The final sample was comparable with similar research exploring the motivations involved in joining the Police (Lester 1983, Tarng et al. 2001; White et al. 2010; Wu et al. 2009).

\section{Materials}

An adapted 14-item survey was used based on the original scale developed by Lester (1983) listing respectively 14 reasons for joining the Police. The survey has been used and adapted extensively in several studies exploring the motivations driving individuals to become Police officers (Raganella and White 2004; White et al. 2010). In the current study, some of the factors used by Lester remained intact (e.g., prestige, power and authority, no other jobs, early retirement, job security); some have been slightly reworded (e.g., "good salary" changed to "steady salary," "having friends and family who were Police officers" changed to "friends and family influence," "good companionship with your co-workers" changed to "teamwork and close relationship," "fight crime" changed into "implement justice"). "Job excitement" from Lester's seminal paper was removed as factor loadings in the original study were low, while a new motive was added to suit the 
contemporary recruitment tactics used by Police Forces, that is, "media influence." Using a Likert 3-point rating scale, (ex)recruits were asked to rate the degree of influence of each factor (i.e., no influence, some influence, very influential; values of 1,2, and 3 were respectively used). Respondents also reported their gender, age (during the study), year and country of recruitment, and age first recruited for the Police.

\section{Analytical Approach}

Past research adapting Lester's questionnaire have either processed the items individually (Raganella and White 2004; Tarng et al. 2001; White et al. 2010) or factor-clustered them into distinct constructs (Wu et al. 2009). The former approach whereby the individual items (reflecting the specific reasons for joining the Police) are used in multiple parametric inferential analyses is potentially problematic. So, despite the use of ( 3 or 4 point) ordinal scales, researchers have computed and used means in subsequent analysis utilizing ANOVA, $t$-tests, or other parametric tests. It is proposed that computing and using means from ordinal-scale items is controversial as the intervals between the options cannot be presumed equal; hence, any relevant findings can be deemed questionable (Jamieson 2004; Norman and Blaikie 2003) unless they are used purely for exploratory or pilot-testing purposes (Allen and Seaman 2007).

While the original research from Lester (1983) and subsequent adaptations (Wu et al. 2009) have already clustered the reasons for joining the Police into district factors, they individually used rather uniform cohorts. On the contrary, the sample of this study consisted of a rather diverse group of (ex) recruits from 28 countries; hence, the structure of the questionnaire was retested using a PCA before any subsequent analysis takes place.

Ultimately, as explained in detail in Results, PCA was used to reduce the number of items into meaningful factors. Subsequently, total scores for the factors were processed to ascertain whether participants from developed and developing countries differed in terms of the reasons they used when deciding to join the Police. Single items not responding to a factor were processed using Mann-Whitney $U$ non-parametric tests. Regression analyses were further conducted to ascertain whether age and year of joining the Police can account for variation in the motives.

\section{Results}

A PCA was performed to cluster the 14 factors that may influence one's decision to choose a career in policing. Kaiser's rule of maintaining eigenvalues P1.0 was adopted. KaiserMeyer-Olkin measure of sampling adequacy was 0.78 with values between 0.5 and 0.7 being acceptable and $0.7+$ being good to excellent (Hutcheson and Sofroniou 1999). To ensure that there were sufficient correlations between items to conduct the PCA, Bartlett's test of sphericity was also performed and found significant at the $p<.001$ level. The PCA was conducted on the 14 factors exhibited with varimax rotation. Using both the screen plot and the eigenvalues $>1$ to determine the underlying component, the analysis yielded 5 components explaining a total of $67.16 \%$ variance.

Table 1 shows the factor loadings following rotation, which suggest that cluster one was represented by four items relating to the social capital attributed to the profession (i.e., power and authority, prestige, and influence by media \& friends). Factor 2 was represented by 6 items relating to job availability and benefits (i.e., only job I was contacted for, no other available jobs, job security, steady salary, early retirement, try until something else turns up). Job security and try until something else comes up were also negatively loaded to factors 1 and 3, respectively. Factor 3 was represented by two items relating to family and friends (i.e., helping family and friends, family influence). Finally, factors 4 and 5 were represented by single items, namely, implement justice (cluster four) and teamwork and close relationships (cluster five).

Once the survey items were reduced to five factors, the internal consistency of factors 1-3 (consisting of at least two items) was computed to ascertain whether they do reliably measure independent clusters and subsequently processed in analysis as total scores. Analyses displayed a high internal consistency for factors 1 (Cronbach's alpha $=0.78$ ) and 2 (Cronbach's alpha $=0.75$ ) but low internal consistency for factor 3 (Cronbach's alpha $=0.40$ ). Total scores were correspondingly computed for factors 1 and 2 for all subsequent analyses (items loaded in factor 3 were treated independently as were single-item factors 4 and 5).

\section{Variations in Motives for Police Officers from Developing and Developed Countries}

Two between-subjects $t$-tests were conducted to assess whether there were differences in factors 1 and 2 between participants from developed and developing countries. Job availability and benefits-driven motives received significantly higher scores among participants from developing countries $(\mathrm{M}=$ 11.28, $\mathrm{SD}=2.39$ ) than from participants from developed countries $(\mathrm{M}=9.16, \mathrm{SD}=1.90, t(231)=4.87, p<0.001)$. No differences were found for social-capital motives.

Factors 3-5 consisting of four items in total were analyzed using four Mann-Whitney $U$-tests. Participants from developing countries scored higher than participants from developed countries in motives related to helping family and friends $(U=4422.00, z=-4.43, p<0.001)$ and family influence $(U=5758.50, z=-2.13, p<0.05)$ but were not significantly different in motives relating to implementing justice and building teamworking and close relationships. 
Table 1 Principal component analysis of motivators influencing one's decision to become a Police officer

\begin{tabular}{|c|c|c|c|c|c|}
\hline & \multicolumn{5}{|c|}{ Rotated components } \\
\hline & 1 & 2 & 3 & 4 & 5 \\
\hline Eigen values & 2.92 & 2.75 & 1.41 & 1.22 & 1.11 \\
\hline Variance $(\%)$ & 20.83 & 19.63 & 10.04 & 8.70 & 7.95 \\
\hline Power and authority & 0.79 & 0.02 & 0.06 & 0.16 & 0.03 \\
\hline Prestige & 0.81 & 0.06 & 0.11 & 0.12 & 0.02 \\
\hline Media influence & 0.75 & -0.20 & 0.06 & -0.12 & 0.06 \\
\hline Friends' influence & 0.68 & -0.24 & 0.04 & -0.07 & -0.18 \\
\hline Only job I was contacted for & -0.04 & 0.87 & -0.06 & -0.07 & 0.06 \\
\hline No other available jobs & -0.13 & 0.83 & -0.01 & -0.12 & 0.01 \\
\hline Job security & -0.58 & 0.53 & 0.14 & 0.02 & -0.18 \\
\hline Steady salary & -0.34 & 0.53 & 0.25 & 0.15 & -0.27 \\
\hline Help friends and family & -0.04 & 0.24 & 0.75 & 0.01 & -0.10 \\
\hline Family influence & 0.37 & -0.20 & 0.69 & -0.02 & 0.07 \\
\hline Early retirement & -0.02 & 0.51 & -0.51 & 0.37 & -0.19 \\
\hline Implement justice & 0.07 & -0.02 & -0.10 & 0.78 & 0.23 \\
\hline Try until something else comes up & 0.02 & 0.55 & -0.08 & -0.60 & 0.14 \\
\hline Teamwork and close relationship & -0.03 & 0.01 & 0.01 & 0.14 & 0.92 \\
\hline
\end{tabular}

Factors highlighted in bold load above 0.5 and are considered significant

\section{Motivations by Year and Age Recruited}

Two multiple regressions were further conducted to ascertain the relative stability of motivations overtime and whether the age and year joining the Police do together affect social-capital motives (model 1) and job availability and benefits-driven motives (model 2). Respectively, the year when participants first joined the Police and their age at the time were used as predictors and the total scores for factors 1 and 2 used as outcomes.

Model 1 significantly explained approximately $30 \%$ of the variance in social-capital motives $\left(R^{2}=0.30, F(2,232)=\right.$ $48.42, p<0.001)$. Results also showed that the age at the time of recruitment was inversely associated with the social-capital motive scores $(\beta=-0.54, p<0.001)$, while the year first joined the Police was not $(\beta=-0.010, p>0.05)$. Model 2 significantly explained approximately $26 \%$ of the variance in job availability and benefits-driven motives $\left(R^{2}=0.26, F(2\right.$, $232)=40.38, p<0.001)$. Results showed that the age at the time of recruitment $(\beta=0.48, p<0.001)$ and the year $(\beta=$ $0.14, p<0.05$ ) of recruitment were associated with the job availability and benefits-driven motive scores. Regression analysis overall showed that the younger the age of joining the Police, the more likely to be motivated by social-capital factors (see model 1). Conversely, job availability and benefits-driven motives kicked off at a later age (see model 2). However, those recruited in more recent years were more likely to consider such motives, hinting that job availability and benefits-driven motives are potentially more appealing in recent years among those joining the Police (whereas socialcapital motives are not).
Since all remaining motives were represented by single items, ordinal regression was considered the most appropriate approach (Lai et al. 2010; Wu and Sun 2010) providing that the proportional odds assumptions were met (using a test of parallel lines). Series of ordinal logistic regressions were conducted to investigate whether the age and year of recruitment could affect the ranking of motives represented by single items, namely, helping family and friends, family influence, implementing justice, and building teamworking and close relationships. Table 2 presented the results of ordinal logistic regression. The results suggested that an increase in age of recruitment (expressed in years) was significantly associated with a decrease in the odds ranking family influence too high with an odds ratio of $.58(95 \%$ CI, .50 to .68), Wald $\chi 2(1)=$ $57.86, p<.001$. Age and year of recruitment were not further associated with the remaining motives.

\section{Discussion}

This study constituted one of the first attempts to provide a global snapshot of the motives leading individuals to decide to work for the Police focusing on the differences among those recruited in developing and developed countries. Considering the uniformity of samples used in past research, the study employed a diverse sample to also capture whether the age and year recruited may affect the motives. The results showed that participants from developing countries scored higher motives related to job availability and benefits (i.e., only job I was contacted for, no other available jobs, job security, steady 
Table 2 Ordinal logistic regression models predicting motives represented by single items

\begin{tabular}{lllll}
\hline & $\begin{array}{l}\text { Family } \\
\text { influence }\end{array}$ & $\begin{array}{l}\text { Helping family } \\
\text { and friends }\end{array}$ & $\begin{array}{l}\text { Implementing } \\
\text { justice }\end{array}$ & $\begin{array}{l}\text { Building teamworking } \\
\text { and close relationships }\end{array}$ \\
\hline Age of recruitment & $\mathrm{b}(\mathrm{SE})$ & $\mathrm{b}(\mathrm{SE})$ & $\mathrm{b}(\mathrm{SE})$ & $\mathrm{b}(\mathrm{SE})$ \\
Year of recruitment & $0.58(0.71) *$ & $0.97(0.06)$ & $0.89(0.02)$ & $0.98(0.06)$ \\
Pseudo $R^{2}$ (Nagelkerke) & $0.10(0.20)$ & $1.00(0.01)$ & $1.02(0.07)$ & $1.00(0.01)$ \\
\hline
\end{tabular}

*Statistically significant association at the $p<0.0001$ level salary, early retirement, try until something else turns up), helping family and friends, and family influence. No significant differences were found in all other motives. Further analysis showed that the younger the age joining the Police, the more likely to be motivated by social-capital motives (i.e., power and authority, prestige, and influence by media \& friends). Conversely, job availability and benefits-driven motives were scored highly among older recruits and those recruited more recently. An increase in age of recruitment (expressed in years) was significantly associated with a decrease in the odds ranking the influence of family too high.

The findings offer an overall unique insight into the range of factors that may motivate individuals to join the Police service, looking beyond the influence of factors such as gender and race whose influence was emphasized in past research (Gibbs 2019; Raganella and White 2004; White et al. 2010). This is the first study to compare the motives of joining the Police attracting a small sample of respondents from 28 countries, further splitting them into two clusters. Our research showed that participants from developing countries scored higher motives related to job availability and benefits, helping family and friends and family influence. One would have expected collectivist values such as helping family and friends to emerge from developing countries, as this study showed, however, the findings were revealing for one more reason. Although job availability and benefits are ranked highly as shown in studies based around the globe (Chu 2018; Lester 1983; Moon and Hwang 2004; Raganella and White 2004; Tarng et al. 2001; White et al. 2010; Wu et al. 2009), this is the first study to show that those living in countries with overall worse economic conditions are more likely to be motivated by job availability and benefits-related motives and ultimately apply with those in mind, to join the Police UN's and World Bank classification of countries change overtime with some countries provisionally clustered in transitional status. This hints that the focus should not be on particular countries, as country classification might change overtime, but on why job availability and benefits seem to be the more appealing reasons to join the Police in countries with greater financial pressures. So, working for the Police may progressively become a more appealing professional option for those seeking some economic stability in both developing and developed countries. Indeed, in one of the very few studies where the year of recruitment was controlled, it was shown that those recruited in 1983 did not rate as high motives related to salary, retirement benefits, and job security compared with those recruited about 23 years later (Foley et al. 2008). So, although several factors were critically important in both samples used by Foley et al. (2008), job-related benefits became even more appealing in recent years. This reflects the fluidity of motives overtime and the need to recruit participants from different countries and cohorts so that an overall greater variability is achieved.

In contrast to job benefits and availability motives, socialcapital motives (i.e., power and authority, prestige, influence by media $\&$ friends) were not associated with the year of recruitment. Past research has shown that while some motives that relate to social capital, such as power and authority that come with the job, have been rated more highly in recent years, other similar motives, such as job prestige, have remained steady overtime (Foley et al. 2008). Bearing in mind that Foley and colleagues used two US-based samples, it is not surprising that changes overtime differed between the two studies, i.e., their study and ours. Yet, what is remarkable is that in both Foley et al.'s and our paper, none of the motives were given a lower rating in recent years; that is, while some motives were scored higher, none of the motives received a lower rating, cautiously hinting that Police work may progressively appear more appealing. Still, motives to join or to keep working for the Police do dynamically change as is the nature of public-Police engagements. Shootings of innocents or excessive use of power by Police Forces around the globe ultimately shake public-Police interactions and lead to a demonization of Police actions. This has ultimately led to a deskilling effect; that is, de-policing trends that ultimately lead to crime rise, due to Police reluctance and fear to engage with the public as the perceived risk of Police actions mislabelled by the public or the press is seen as high, even in circumstances where Police actions are legitimate (Wolfe and Nix 2016). Tentatively termed as the "Fergusson effect," such a phenomenon may change the landscape of motives of those who are yet to join the Police or make the prospect of joining the Police less appealing altogether.

Bearing in mind the low age variability of past research samples, it is not surprising that this was the first study highlighting the diversity of motives among a sample 
consisting of individuals recruited at various ages. The younger recruits prioritized social-capital motives and were more likely to be influenced from family, while the older recruits were more likely to rate highly job availability and benefits. Bearing in mind the low age of those recruited in some Police colleges as cadets (as young as 14 years old in our sample), and subsequently continued working for the Police, it is reasonable that financial concerns are not as urgent in younger ages and they might kick-off at a later age. This hints that it might be fruitful to explore the motives of younger recruits enrolled in Police colleges as teenagers to fully appreciate the map of motives among Police officers. Job availability and benefits have been rated high among several studies including this one; however, the ranking of motives presented in the literature has so far neglected those recruited as young as 14 in Police colleges and subsequently worked as Police officers. Indeed, most of the studies identified have either completely omitted the age of recruitment (e.g., Foley et al. 2008; Gibbs 2019; White et al. 2010; Wu et al. 2009) or included a very short range of ages within which participants were recruited (e.g., Tarng et al. 2001). It is reasonable to omit the age of recruitment if most participants are of similar age but as this study has highlighted, the age range of recruits varies around the globe, so this is a moderator that must be considered in future studies. Crucially, bearing in mind the diversity in recruitment tactics, globally, it is important for future research to look even beyond age of recruitment and somewhat capture how recruitment tactics and time spent in training camps and colleges may have affected the motives, gathering responses before and after initiation training (e.g., see White et al. 2010).

\section{Limitations}

A clear weakness of this research is that participants of various ages were included, meaning that the year of recruitment could have been as far as the 1970s for some participants. Although the year of recruitment was recorded and used in some of the analysis, it is very likely that subsequent exposure to Police work and the long delay between applying for the Police (college) and taking part in the study may have contaminated their memory recollections regarding the true reasons for joining the Police. This is somewhat inherent in trying to recruit a diverse sample of participants, some of whom were recruited a while ago; still, the findings must be cautiously interpreted, particularly in relation to the influence of age and year of recruitment.

The sample was small to represent the countries included in the study and not large enough to broadly represent the opinions hold in developing and developed countries among those working for the Police. So, clearly, this study cannot represent the motives of those applying to work for the Police worldwide. Still, this was a first attempt to touch upon the motives by looking at two distinct sets of countries incorporating responses from several forces. It is essential that the study is replicated in well-designed studies recruiting larger numbers of participants from both developing and developed countries to obtain a more coherent global overview of the map of factors influencing those joining the Police. In retrospect, our study was heavily influenced by Lester's work and methodology, hence the list of motives factor analyzed might not be comprehensive. For example, job excitement was not incorporated in the list of motives as factor loadings were low in Lester's (1983) work; hence, it is likely that, alongside this, some other key motives were missed. Future research must correspondingly include a larger array of motives, considering recent research and motives shared by minority officers (e.g., see Gibbs 2019).

\section{Implications of Findings and Recommendations}

The results of this study supported Chu's (2018) preliminary suggestion that financial concerns and limited job availability may shape preferences of young recruits. Beyond Chu's (2018) study, a comparison between recruits from different countries or geographical regions could not be found in the known literature. The increasing popularity of motives involving the job security provided by a career in Police, as also shown in Foley et al. (2008), may be a hint that crosssectional designs might be only partially helpful as they cannot capture changes of preferences overtime. Still, the preference for a career in Police in recent years and among those recruited in developing countries might simply reflect that the greater the financial pressures experienced by the applicant, the more likely to apply to work for the Police to secure financial stability. Bearing in mind that the samples from Chu (2018) and Foley et al. (2008) are rather different from the sample we used, it is tentatively proposed that financial pressures might supersede the influence of other factors examined in the literature, such as gender and race. Indeed, past research has showed that those from a lower socioeconomic status were more likely to be interested in job security and steady salary (Moon and Hwang 2004; Tarng et al. 2001), yet such research recruited participants from a single country. Also, socioeconomic status was not measured in relative terms but was instead designed to capture several peripheral indicators, such as family members' education and occupation (Tarng et al. 2001) that might not directly reflect financial pressures in a global landscape. Although research in underage populations is scarce and hard to ethically balance, it might be fruitful to ascertain the motives of those recruited as adolescents in Police or cadet colleges who subsequently pursue a career in Police. Similarly, including those who started a career in Police at a later stage in their lives might be fruitful to overall allow older recruits to be represented. As this study has shown, the age of recruitment may moderate the ranking of motives; therefore, future studies should attempt to 
capture it to extract a clear snapshot of the motives that prevail in joining the Police.

\section{Conclusions}

This study compared motives driving people to join the Police in developed and developing countries. The findings suggested that job availability and benefits-driven motives, family influence, and helping family and friends were scored or ranked more highly in developing countries. The results also revealed that motives to become a Police officer are changing overtime and benefits-driven motives have seemed more appealing in recent years, while family influence was rated significantly higher by younger recruits than those who joined the Police at older age. More research focusing on those who joined the Police force at a young age and a greater emphasis on the dynamic changes of motives is encouraged. If some motives, for example, do progressively become more appealing, overtime, than others, then the trends must be highlighted so that Police recruitment strategies and overall management of new recruits are accordingly shaped. Similarly, if financial motives are indeed of core importance among those joining the Police, then a review of the role of financial motives to continue working for the Police will be fruitful to ascertain whether the extent to which original motives have been fulfilled may affect the quality of work for personnel. For example, White et al.'s (2010) work has proposed that motive fulfillment is associated to subsequent job satisfaction so that low fulfillment of a motive leads to lower job dissatisfaction. Interestingly, they also reported a notable interplay between motivations for joining the Police and later job satisfaction with those recruited because there were no alternative job opportunities or due to early retirement displaying higher dissatisfaction with the job 6 years after recruitment than those reporting more altruistic motives. These findings suggest that motives for joining the Police may be good markers for subsequent job satisfaction, hinting again that motives for joining the Police can inform Police recruitment and management.

\section{Compliance with Ethical Standards}

Conflict of Interest The authors whose names are listed immediately below certify that they have NO affiliations with or involvement in any organization or entity with any financial interest (such as honoraria; educational grants; participation in speakers' bureaus; membership, employment, consultancies, stock ownership, or other equity interest; and expert testimony or patent-licensing arrangements) or non-financial interest (such as personal or professional relationships, affiliations, knowledge or beliefs) in the subject matter or materials discussed in this manuscript.

Ethical Approval This research was conducted in accordance with BPS and APA research ethics guidelines and approved by the University of Liverpool, Institute of Psychology, Research Ethics Committee.
Informed Consent Standard procedures for gaining informed consent were used, and participants were informed of their right to withdraw from the study at any point without having any obligation to explain their reasons for withdrawing.

Open Access This article is licensed under a Creative Commons Attribution 4.0 International License, which permits use, sharing, adaptation, distribution and reproduction in any medium or format, as long as you give appropriate credit to the original author(s) and the source, provide a link to the Creative Commons licence, and indicate if changes were made. The images or other third party material in this article are included in the article's Creative Commons licence, unless indicated otherwise in a credit line to the material. If material is not included in the article's Creative Commons licence and your intended use is not permitted by statutory regulation or exceeds the permitted use, you will need to obtain permission directly from the copyright holder. To view a copy of this licence, visit http://creativecommons.org/licenses/by/4.0/.

\section{References}

Allen IE, Seaman CA (2007) Likert scales and data analyses. Qual Prog 40(7):64-65

Anshel MH (2000) A conceptual model and implications for coping with stressful events in police work. Crim Justice Behav 27(3):375-400

Boyce G, Davids C (2009) Conflict of interest in policing and the public sector: ethics, integrity and social accountability. Public Manag Rev 11(5):601-640

Brandl SG, Stroshine MS (2003) Toward an understanding of the physical hazards of police work. Police Q 6(2):172-191

Chu DC (2018) Employment motivation and job-related satisfaction: a comparison of police women's perceptions in Dubai and Taipei. Polic Soc 28(8):915-929

Collins PA, Gibbs ACC (2003) Stress in police officers: a study of the origins, prevalence and severity of stress-related symptoms within a county police force. Occup Med 53(4):256-264

Cooper C, Ingram S (2004) Retention of police officers: a study of resignations and transfers in ten forces (no. 86). Research, Development and Statistics Directorate, Home Office

Elntib S, Armstrong T (2014) Critical incidents' impact on front-line South African police personnel in light of the current briefing and debriefing strategies. S Afr J Psychol 44(4):416-425

Elntib S, McPherson P, Ioannou M, Addy D (2018) When sex is more than just sex: evaluating police perspectives regarding the challenges in interviewing victims of sexual offences in Jamaica. Polic Soc: $1-21$

Foley PF, Guarneri C, Kelly ME (2008) Reasons for choosing a police career: changes over two decades. Int J Police Sci Manag 10(1):2-8

Gau JM, Terrill W, Paoline EA III (2013) Looking up: explaining police promotional aspirations. Crim Justice Behav 40(3):247-269

Gershon RR, Barocas B, Canton AN, Li X, Vlahov D (2009) Mental, physical, and behavioral outcomes associated with perceived work stress in police officers. Crim Justice Behav 36(3):275-289

Gibbs JC (2019) Diversifying the police applicant pool: motivations of women and minority candidates seeking police employment. Crim Justice Stud:1-15

Harrendorf S, Heiskanen M (2010) In: Malby S (ed) International statistics on crime and justice. European Institute for Crime Prevention and Control, affiliated with the United Nations (HEUNI)

Hutcheson G, Sofroniou N (1999) The multivariate social scientist. Sage, London

Jamieson S (2004) Likert scales: how to (ab) use them. Med Educ 38(12): $1217-1218$ 
Lai YL, Cao L, Zhao JS (2010) The impact of political entity on confidence in legal authorities: a comparison between China and Taiwan. J Crim Just 38(5):934-941

Lester D (1983) Why do people become police officers: a study of reasons and their predictions of success. J Police Sci Adm 11(2):170 174

Moon B, Hwang E (2004) The reasons for choosing a career in policing among. South Korean police cadets. J Crim Justice 32:223-229

Norman B, Blaikie H (2003) Analysing quantitative data: from description to explanation

Oberfield Z (2014) Motivation, change, and stability: findings from an urban police department. Am Rev Public Adm 44(2):210-232

Raganella AJ, White MD (2004) Race, gender, and motivation for becoming a police officer: implications for building a representative police department. J Crim Just 32(6):501-513

Scarborough KE, Van Tubergen GN, Gaines LK, Whitlow SS (1999) An examination of police officers' motivation to participate in the promotional process. Police Q 2(3):302-320

Tarng MY, Hsieh CH, Deng TJ (2001) Personal background and reasons for choosing a career in policing: an empirical study of police students in Taiwan. J Crim Just 29(1):45-56

The World Bank (2014) World Development Indicators. Retrieved from: http://documents.worldbank.org/curated/en/752121468182353172/ pdf/879460PUB0REPL00Box385214B00PUBLIC0.pdf . Accessed Jun 2, 2019
United Nations (2014) World economic situation and prospects. Retrieved from https://unctad.org/en/PublicationsLibrary/ wesp2014_en.pdf.Accessed July 2015

Vila B (2006) Impact of long work hours on police officers and the communities they serve. Am J Ind Med 49(11):972-980

Vila B, Morrison GB, Kenney DJ (2002) Improving shift schedule and work-hour policies and practices to increase police officer performance, health, and safety. Police Q 5(1):4-24

Violanti JM (1990) Police retirement: the impact of change. FBI Law Enforcement Bulletin 59(3):12-15

White MD, Cooper JA, Saunders J, Raganella AJ (2010) Motivations for becoming a police officer: re-assessing officer attitudes and job satisfaction after six years on the street. J Crim Just 38(4):520-530

Wolfe SE, Nix J (2016) The alleged "Ferguson effect" and police willingness to engage in community partnership. Law Hum Behav 40(1):1-10

Wu Y, Sun IY (2010) Perceptions of police: an empirical study of Chinese college students. Polic Int J Police Strateg Manag 33(1): 93-113

Wu Y, Sun IY, Cretacci MA (2009) A study of cadets' motivation to become police officers in China. Int J Police Sci Manag 11(3): $377-392$

Publisher's Note Springer Nature remains neutral with regard to jurisdictional claims in published maps and institutional affiliations. 